\title{
Contribution of Revived Heritage on Contemporary Social Interaction: The Case of Paddington Reservoir Garden
}

\author{
Yunjin Wang* \\ Queensland University of Technology, Tangshan 063000, China \\ *Corresponding author: Yunjin Wang, 929999811@qq.com
}

\begin{abstract}
Reviewing and further reviving the historical landscape have significant impacts on developing this field for the designers ${ }^{[1]}$. It is useful for contemporary designers to learn from the past. They can practice analyzing the strengths and weaknesses of diverse past examples, recognizing the success criteria of contemporary designed landscapes, and exploring new ways to design sustainable public spaces for the future. This article will examine the Paddington Reservoir Garden, in Paddington, Sydney, Australia. This is as a successful and influential example as a heritage redesigned as a contemporary public open space.
\end{abstract}

Keywords: Revived heritage; Historical landscape; Contemporary social interaction

Publication date: July 2021; Online publication: July 31, 2021

\section{Introduction}

Based on the vital role that heritage plays in history of human art, culture and architecture, contemporary designers should to deliberate what is vital to modern society on producing a usable past. Start from this question, this article aims to explore how people revive the discarded heritage, improving its functions and creating new meaningfulness on modernity values. This article selects a typical heritage work, the Paddington Reservoir Garden (PRG), in Sydney, Australia. This is a heritage which display a combination of contemporarily creative intervention and original old construction. By analyzing the significance and effect in terms of social, environmental and aesthetic values, the effective ways to revive the heritage could be summarized and put forward.

\section{Analysis progress}

The Paddington Reservoir Garden was a significant water source catering to the rapidly growing population in the 19th century and ceased operations in 1899. Tonkin Zulaikha Greer and JMD Design redesigned this place and construction spanned from 2006 to $2009^{[2]}$. Nowadays it is an outstanding public space integrating historical foundations and contemporary elements to provide the visitors with multiple opportunities. It reflects how a historical space can become a vital contemporary space, also create precious opportunity for the contemporary designer to rethink the historical landscape works functioning in the future.

\section{Social value analysis}

The discussion starts with its social values. The social value of one public space is exhibited by its ability of social connection ${ }^{[3]}$. It implies that a successful contemporary designed landscape should have the capacity to form a strong social connection between the visitors and itself. One approach is to provide 
multiple facilities and services to cater the public's needs of their physical and mental aspects, for example, infrastructure, amenities and natural view ${ }^{[3]}$. These factors can inform, inspire and link people and the environment effectively ${ }^{[4]}$. Taking the PRG as an example, its highly social value is displayed by its comfortable and safe infrastructures, diverse cultural facilities and artistic natural elements.

\subsection{Benefits}

There are two main features facilitating the achievement of the high social value of this heritage. Afford of fundamental infrastructure play a vital role in strengthening social interaction. By providing the society's basic requirements is to cater the convenient and comfortable experience. The installed infrastructures in PRG are considered to cater to the users' multiple needs, including the elevator, the wide boardwalk, and benches (Figure 1.). Through using them, the interaction between the visitor and this public space could be strengthened.
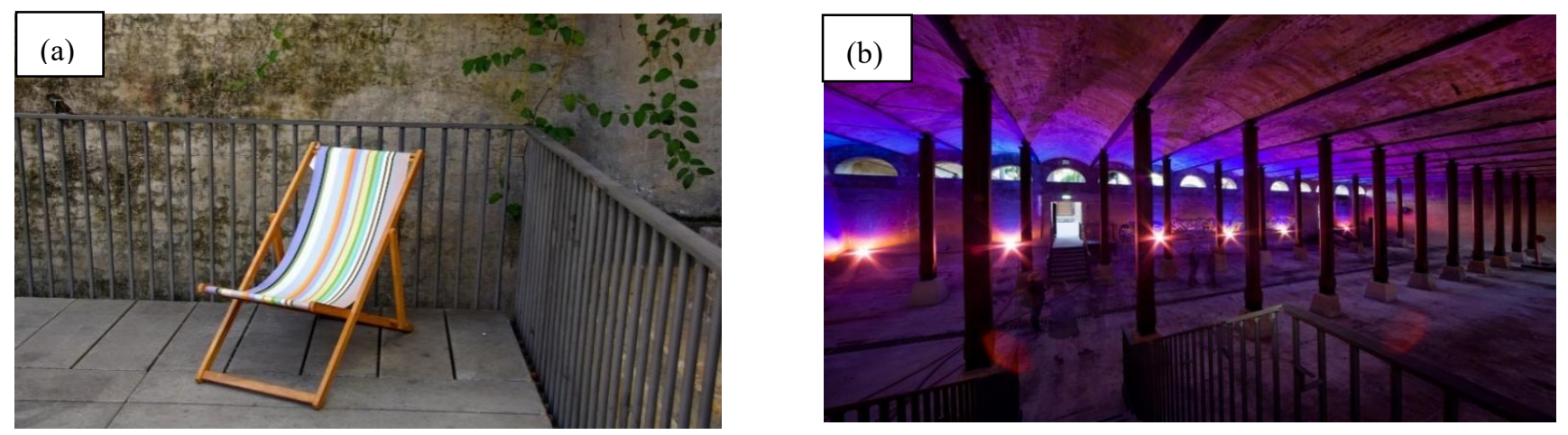

Figure 1. (a) Leanne Barnett as shown in Knowing where to stand, 2013; (b) Eric Sierens as shown in “tonkinzulaikhagreer" Architects, n.d. ${ }^{[5-6]}$

\subsection{Weaknesses}

Although applying the former two reviving techniques on this historical space can prove its highly social values in the contemporary period, there are still two shortcomings with hindering the further improvement of the values. Firstly, the garden still exists under-maintained infrastructure ${ }^{[7]}$. For example, the elevator with poor cleanliness for a long time is reducing the visitors' desire to use it. The second negative factor is the unobvious signage displayed on the garden entry gate. Its design ought to have the noticeable characteristics to gather social groups to this site ${ }^{[8]}$. The signage of the gardens' name on the gate is too inconspicuous to be noticed by the visitor (Figure 2.). This weakness could deprive the common guests' opportunities to engage in this site, and impede them to connect with more social groups.

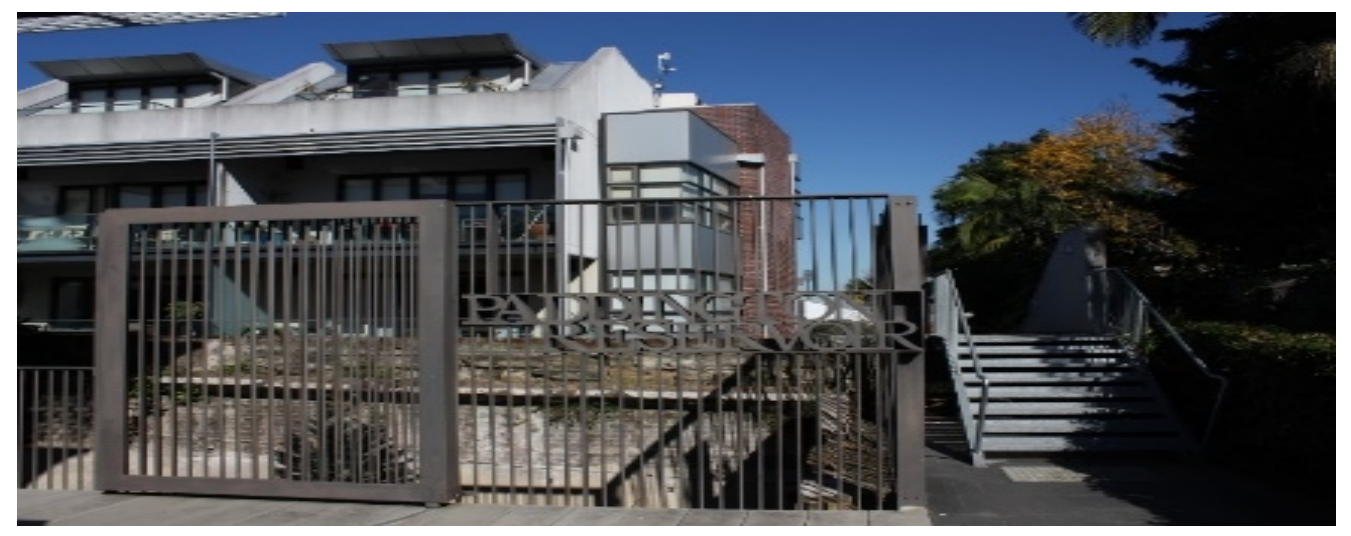

Figure 2. Jim as shown in Sydney-City and Suburbs, 2013 [9] 


\section{Environmental value analysis}

The application and expression of sustainability ethics in designed landscapes could have vital impacts on environmental protection ${ }^{[10]}$. Based on the design teams of the Paddington Reservoir Garden, Tonkin Zulaikha Greer, and JMD Design's sustainable design concept, this public open space has become a typical contemporary example that involves advanced sustainability ethics. There are two applied approaches in this site to strengthen its environmental values, decreasing the waste of materials through reusing past resources and maintaining a local ecological system with scientific humanistic intervention.

\subsection{Benefits}

Firstly, as water storage in the past, PRG had to be closed in 1899 because of collapsed roof and lack of primary functions (Figure 3.). Nevertheless, it escaped from the fortune of being discarded and revived with new functions and innovative styles since being redesigned. Their major approaches are to repair its original framework and reuse its old materials, including historic brick, cast iron and timber.

Secondly, proper anthropogenic intervention to natural resources could be more beneficial to the ecology cycle in a designed landscape ${ }^{[11]}$. In the PRG, there are multiple natural ornaments, such as plant collections, lawns, and ponds. The placement of these natural components is an artificial way to increase the richness of nutrition and necessary energy of the public space, for example, the pond. It provides this space adequate water resources.

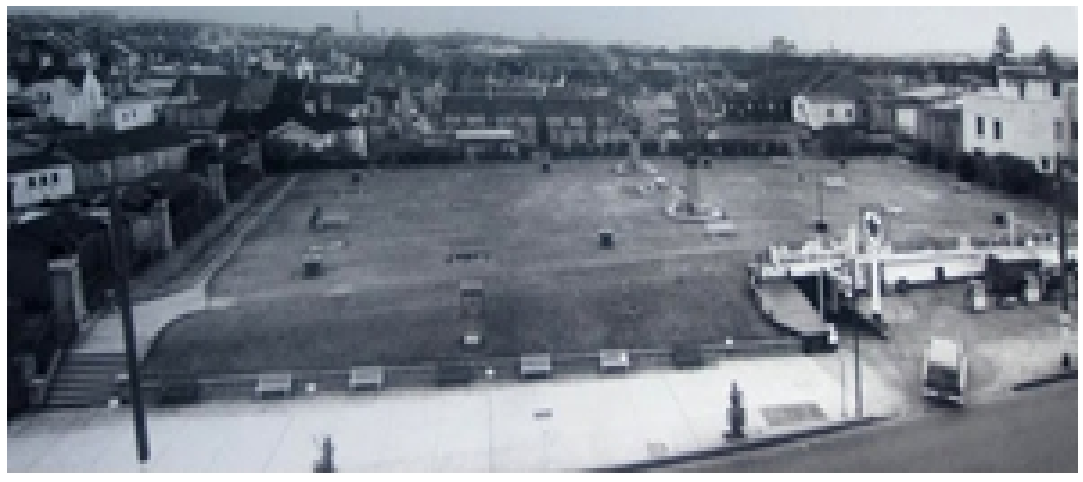

Figure 3. Sally cited in Sydney Daily Photo, $2009^{[12]}$

\subsection{Weaknesses}

Lundholm argues that the vegetation coverage could impact the sustainable development of the urban environment positively [13]. However, in the PRG, the density of green plants is one limitation of its environmental value. The major function of the vegetation in this public open space is decoration.

\section{Aesthetics value analysis}

Displaying precious cultural scenes to the visitors is a vital aspect to illustrate the aesthetic value of a contemporary garden ${ }^{[14]}$. PRG is a typical example.

\subsection{Benefits}

Firstly, the historical aesthetics value of the Paddington Reservoir Garden is its heritage. The vital original framework in this public open space is preserved completely by designers, such as major linear structures, vaulting, and walls with distinctive curved characteristics (Figure 4.). Secondly, the cultural aesthetics values of the designed landscape also are presented in terms of its contemporary design of roof-top, architecture structure, and artifacts. The obvious instance is the roof-top with a sunken characteristic is inspired by the Baths of ancient Caracalla, now becomes a modern feature and applied 
widely in contemporary public space ${ }^{[15]}$.

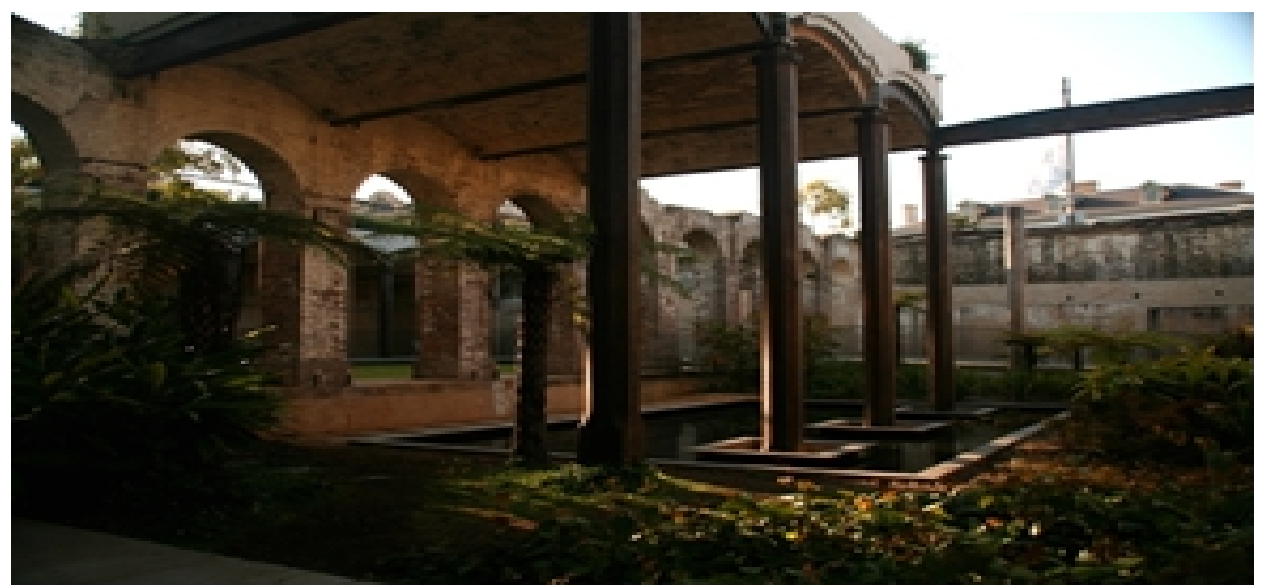

Figure 4. Christopher Yardin as shown in Something for Kiki and the Pok, $2013^{[16]}$

\subsection{Weaknesses}

A few infrastructures breaking the aesthetic harmony of this space. Some details in their design could not match the major aesthetics style of this designed landscape. For example, the structure of the garden fences, texture of stair pavement and the color of deck chairs are discordant compared with other elements in this space (Figure 5, 6).

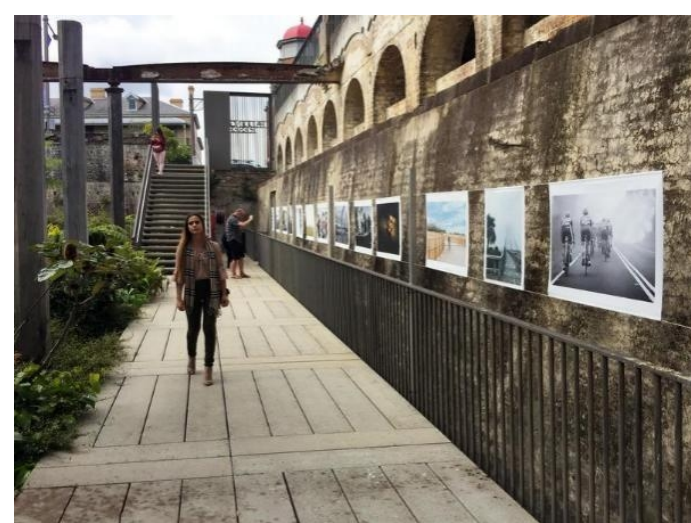

Figure 5. Lauran Vohmann as shown in hEAdoN photo festival, $2017^{[17]}$

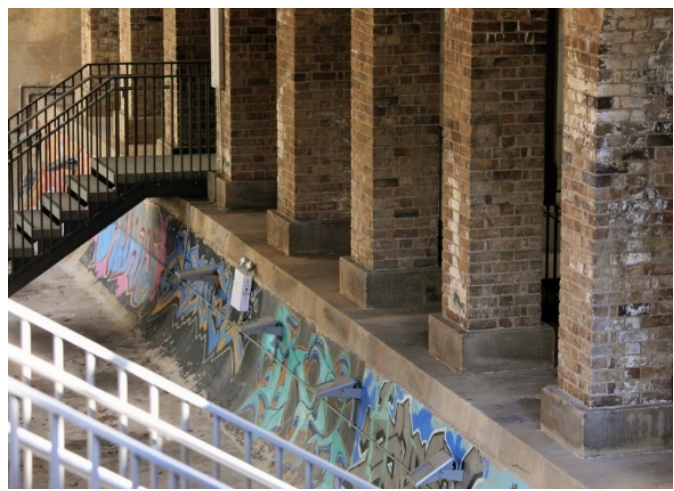

Figure 6. Alex Promios as shown in flickr, 2009 [18]

\section{Discussion}

Based on the analysis for this garden in terms of social value, environmental value and aesthetic value, there is no doubt that this space which has a highly meaningfulness for the contemporary as a heritage. As 
the discussion, in these three aspects, this space still has a high value which can improve. However, the value and impact of this landscape still worthy to be analyzed and emphasized. The most vital benefits for this site include that the instalment of the artificial equipment and the recreation of the ecological system. The combination of the contemporary elements and the historical construction can create a new experience journey for the visitors.

\section{Conclusion}

In conclusion, former contemporary gardens exist advantages which are worthy to be learnt for future designers. They also have several disadvantages which could be avoided and improved. The author selected the Paddington Reservoir Gardens, an old reservoir which is revitalized through being redesigned as an example. Its strengths and weaknesses were analyzed in three aspects, including social values, environmental values and aesthetics values. Even though this contemporary public space still has several aspects which need to be promoted in the future, it does inspire and encourage designers to design a contemporary landscape with benefits in terms of social interaction, environmental sustainability and aesthetics values, just like itself, even better.

\section{Disclosure statement}

The author declares no conflict of interest.

\section{References}

[1] Bucher A, 2014. Topology Topical Thoughts on the Contemporary Landscape. Berlin: JOVIS Verlag.

[2] De Manincor J, 2009. "Paddington Reservoir Gardens" Architecture Review Australia 110. https://heritagecouncil.vic.gov.au/wp-content/uploads/2014/08/Paddington-Reservoir-Gardens.pdf

[3] Uren HV, Dzidic PL, et al., 2015. "Exploring Social and Cultural Norms to Promote Ecologically Sensitive Residential Garden Design.” Landscape and Urban Planning 137: 76-84.

[4] Silverman W, 1982, "The Social Life of Small Urban Spaces." Urban Life. http://search.proquest.com/docview/61786442/.

[5] Barnett L, 2013, "Knowing to Where Stand," http://knowwheretostand.blogspot.com.au/2013/11/paddington-reservoir-gardens.html.

[6] Sierens E, "Tonkinzulaikhagreer," Architects, http://www.tzg.com.au/project/paddington-reservoir.

[7] Sun J, 2012. "Strengthen the 'Non-Visual Perception Experience' in the Design of Public Space." Applied Mechanics and Materials, 174-177: 3083-3086.

[8] Mrtony, 2017, “The Paddington Reservoir Garden.” Trip advisor, January 7, 2017. https://www.tripadvisor.com.au/ShowUserReviews-g255060-d2230032-r449934490-Paddington_ Reservoir_Gardens-Sydney_New_South_Wales.html

[9] Jim, 2013, "Sydney-City and Suburbs," https://sydney-city.blogspot.com.au/2013/02/paddington-reservoir-gardens.html.

[10] Danang WP, 2017. "Conservation Value and Environmental Services of the Plant Collections of Botanic Gardens at the Urban Area." Prosiding Seminar Nasional Masyarakat Biodiversitas Indonesia. https://doaj.org/article/c7eecb5099de4bc794300c117de75411.

[11] Buggey S, 1999. "Conservation of Landscapes of Historic and Cultural Value: The Emergence of a Movement.” Environments 26(3): 17-27. http://search.proquest.com/docview/207673019/. 
http://sydneynearlydailyphot.blogspot.com.au/2009/08/paddington-reservoir-garden-bit-of.html.

[13] Lundholm JT, 2015, "Green Roof Plant Species Diversity Improves Ecosystem Multifunctionality." Journal of Applied Ecology 52(3): 726-734.

[14] Cui L, Zhang J, 2011, "Study on Classic Garden Design and its Modern Application from the View of Nature in Both Western and Eastern History." In Electric Technology and Civil Engineering (ICETCE), 2011 International Conference on, 3492-3494. IEEE Publishing.

[15] Sisco L, Monzer S, Farajalla N, et al., 2017. "Roof Top Gardens as a Means to use Recycled Waste and A/C Condensate and Reduce Temperature Variation in Buildings." Building and Environment 117: 127-134.

[16] Yardin C, 2013, "Something for Kiki and the Pok," https://christopheryardin.com/2013/03/05/paddington_reservoir_gardens/

Vohmann L, 2017, "Headon
https:/www.headon.com.au/blog/sydney-rides-festival-2017.

[18] Promios A, 2009, "Flickr," https://www.flickr.com/photos/proimos/4051721653.

[19] Ware SA, Raxworthy J, 2011, "Literal Signigiers: Paddington Reservoir Gardens” in Sunburnt: Landscape Architecture in Australia, 120-127.

[20] Maurizio, 2009, “The Pocket Road.” https://thepocketroad.com/places/paddington.

[21] Boardman B, 2010, "Landscape Architecture Australia," https://andscapeaustralia.com/articles/paddington-reservoir-gardens-aila/.

[22] Twistie M, 2010, "Flickriver," http://www.flickriver.com/photos/twistieman/4763940166/.

[23] Brumley, Wells, 2015, "We Are Origami," http://weareorigami.com.au/chhay-ollies-wedding/.

[24] Cooper LM, 2012, “LMC, Louise M Cooper," http://www.louisemcooper.com/2012/05/head-off. 